\title{
Absence from work attributed to sickness
}

\author{
A. M. ADELSTEIN \\ General Register Office, Somerset House, London, W.C.2.
}

This report ${ }^{1}$ is a record of the two-day discussions organized by the Research Panel of the Society of Occupational Medicine on the subject of absence from work attributed to sickness.

Notice the careful phrasing: absence (from work) attributed to sickness; not sickness absence. After reading this title one is not surprised that much of the discussion is centred on evidence that absence claimed or certified to be the result of illness is markedly influenced (and sometimes entirely determined) by socio-economic and management situations. The sickness is to be seen not only in the bodies and minds but also in the structures and organizations in which they function; the main diagnoses and therapies discussed are not those in the International Classification of Diseases and in texts of medicine; rather they are the concepts of administrators, economists, sociologists, psychologists, and statisticians.

One way of looking at the problem of absence is to see the extremes; on the one hand, absence which has nothing whatever to do with sickness (in the conventional sense) but which is certified by a doctor on the say-so of the man; he may do another job during the period of absence. On the other extreme, there is severe illness during which there is no possibility of work because the man is prostrated. These extreme situations (particularly the first) are relatively rare. What constitutes the root of the problem of absence is illness which in some circumstances stimulates the victim to assume the sick role and, in other circumstances, does not. Here lies some of the difficulty of the intellectual aspects of this discussion; for when sociologists and psychiatrists grapple with the concept of sickness they define it in sociological terms, for example, the sick role. Sickness is more than disorder of the body.

${ }^{1}$ Proceedings of the Symposium on Absence from Work Attributed to Sickness. Edited by A. Ward Gardner. Biography prepared by Peter Froggatt. London, Royal College of Surgeons of England (obtainable from Miss B. M. Key. 12s. 6d. post free).
It has social implications, and the threshold varies with custom, tradition, and many other social factors.

The discussions illustrate an apparent paradox in many aspects of health; for as indicators of health improve in parallel with the socio-economic improvement of the community there is a change in the public perception of what is sickness, and the demand for health services may increase. By a process similar to this change in the public perception of illness there has been noted a relationship between the demand for health services (or the need) and the supply of these services; as the supply improves the need appears to increase. Here again the perception of what is need has changed.

The panel discussed another example of the way ideas of what one is entitled to may change: when a group of workers had decided that they were entitled to more leave and when this had become an aim of their Union, there was an increase in absence attributed to sickness; the speaker said 'the probable explanation of this phenomenon is that social opinion considered that three weeks paid holiday was a proper entitlement and many people were prepared to exercise this right by such means as were socially acceptable'. Even so, at the final session one participant said that he 'felt obliged to state the axiom too often overlooked, the commonest cause of absence from work is sickness, though he would not deny the importance of other factors especially in short term absences'.

The reviewer believes that this argument is, in one sense, academic only, since the remedies proposed are clearly essential in their own right; illness, whatever absence it causes, should be dealt with anyway by all the means at our disposal; and since absence may be a symptom of industrial and social malaise then this also needs to be treated for its own sake, since otherwise there will occur other symptoms such as higher accident and labour turnover rates and, more important, a primary purpose 
of industrial organization - production - will suffer. It does not seem sensible or practical to oppose the introduction of sick-pay facilities which help the majority to be free from the hardships which can accompany periods of illness. In the environment of industrial democracy as we know it, industry which depends on such methods as the withholding of facilities to attempt to keep its men at work can generally be taken to be inefficiently organized by any standards.

Ten papers were read at the conference; nine by doctors and other workers in industrial medicine in the United Kingdom and one paper by a delegate from the Netherlands. The papers were followed by full discussions. Although in general the ideas on absence which were analysed are not new, much of the data presented is, and adds to an understanding of the underlying problem. The discussions were often confined to the subject of short absences, and many factors which influence sources of variation were distinguished; for example, age, sex, category of job, shift or regular work, season of year, day of week, morale, motivation, introduction of automation, level of employment in community, job security, level of responsibility, promotion prospects, sick pay arrangements, private insurance, privilege equalization, urban-rural, doctor, and organization of medical services, e.g., waiting times.

Among the points made were that: in Britain the trend of the number of days lost is upward (but some members doubted the validity of the conclusion); an increase in the sickness benefit leads to increased absence, in particular to longer spells; short-term absence is primarily a problem for management; the present policy of differential (higher) payments for injury and illness certified as due to employment should be revised; management and unions should agree on a policy which encourages convalescents to do what work they can.

An issue of immediate practical importance which may have far-reaching consequences relates to medical certificates for short-term absence; two speakers discussed experience of systems in which doctors' certificates were not required for short-term absence: it was reported that in the Netherlands doctors' certificates are not used as means of trying to control absence or payment. A speaker described an experiment in an oil refinery in the United Kingdom in which absences up to three days were certified by the worker himself, and his conclusion was that the scheme had not encouraged serious absence. Another discussant, the general practitioner, adopted a firm stand when he proposed that the principle of self-certification for absences of up to seven days be adopted. He said that workmen do not want to bother a doctor, and there is evidence that absence may be increased when they do. 'There was a time in my career when I occasionally tried to refuse people certificates - but in the interests of my coronary arteries I have given up arguing about certificates and my attitude is wholly permissive. In any case it is very difficult, if not impossible to refuse to give a certificate ....

A doctor in industry gave his opinion that it was not part of the general practitioner's function to maintain industrial discipline or morale. Finally, on this point, among the suggestions for further research is one to ascertain the effect of self-certificate or no certificate on spells of absence of certain periods.

In addition to the report of the discussions, the publication has an extensive bibliography on 'sickness absence' selected from work in English (and mainly from England), divided into three sections: medical, industrial and economic, statistical and actuarial. The authors say 'we have omitted reference to the contingent fields of psychology and sociology because these are not of prime concern to doctors. ...' However, they add 'excellent review articles and extensive bibliographies to those can be found in Current Sociology, Vol. 9 (1960)'. The statement that psychology and sociology are not of prime concern to doctors is surprising, the more so after reading the opinions held at the conference. After this statement I was surprised to find the title 'The Protestant Ethic and the Spirit of Capitalism', surely sociology, and theoretical. The bibliography ranges widely (with the exception mentioned) over time and subjects and would certainly be a valuable addition to the library of anyone interested in industrial medicine and related subjects. This publication is a must for all workers in this field. 